\title{
Sobre la posición en la Romania de la lengua catalana (I)
}

\author{
Francisco Abad Nebot \\ (UNED) \\ fabad@flog.uned.es \\ Recibido: marzo de 2014. Aceptado: marzo de 2014
}

Resumen: Hacemos un primer panorama -procurando ser concretos- del asunto de la subagrupación románica del catalán.

Palabras clave: Lengua catalana; Galorromania; Iberorromania

\begin{abstract}
The present paper offers a specific overview about the subgrouping of Catalan within the Romance languages family.
\end{abstract}

Keywords: Catalan, Gallo-Romania, Ibero-Romania

$\S 1$. G. Salvador se ha ocupado de lo que él piensa -se deduce de sus escritos- que es la guerra de las lenguas en la Península, y en su recopilación Lengua española y lenguas de España (1987), lleva a cabo afirmaciones literales como las siguientes $(i !)$ :

Se están montando ikastolas, se pretende escolarizar en batúa a los niños. Es decir, se pretende sustituir la segunda lengua natural del mundo por ese revesado e invertido esperanto [ 'el batúa'] (p. 21).

Rebuznan muchos [profesores]. Y los rebuznos se contagian (p. 27).

Me resultan [...] siniestros todos esos movimientos y manipulaciones ideológicas que tienden [...] a aislar a la gente en lenguas minoritarias (p. 86).

Hay trabajos serios en bable, pero escritos así ofrecen irremediablemente un cierto aire de broma (sic, p. 112).

No hay que llamar la atención acerca de lo irrespetuoso de estos pasajes, de su carácter de exabrupto inadecuado para un profesor y un publicista; por desdicha de todos, hay al menos dos o tres profesionales de la filología entre nosotros que se manifiestan en este registro: nosotros desde luego nunca escribiríamos — no lo hemos escrito ni lo escribiremos- algo así. 
El mismo autor dice por igual que el inconveniente del catalán «es que es una lengua minoritaria, que sólo la hablan [...] unos cinco o seis millones de personas»; con mayor fidelidad a los hechos y sobre todo con mayor voluntad de comprensión, en uno de sus manuales de Bachillerato simultáneo a los pasajes transcritos, Fernando Lázaro Carreter escribía por su lado cómo el catalán «resultó de la evolución del latín en la región nordeste de la Península [ y] cuenta con más de siete millones de hablantes», y así en una conferencia de 1999 podía sintetizar que «cerca de diez millones de españoles poseen otra lengua materna» (El nacionalismo lingüístico catalán: orígenes; al parecer el autor deseaba hacer un libro sobre la materia, pero tal obra se quedó en unos fragmentos. Nosotros mismos tenemos hechas lecturas para quizá poder referirnos a la temática).

Resulta muy necesario este aludido espíritu de comprensión — comprensión de los hechos y comprensión intelectual y moral hacia los hablantes-, y de esta manera trazamos unos párrafos panorámicos acerca del idioma catalán y su lugar en la Romania.

$\S 2$. Del año 1925 es el texto Das Katalanische de W. Meyer-Lübke (traducido ahora a la lengua catalana), del que muy esencialmente recogemos:

a) «El sistema fonètic del català és absolutament galloromànic, no pas iberoromànic».

b) «La monoftongació $\mathrm{AU}>o$ i $\mathrm{AI}>e$ sí que és un desenvolupament coincident» en español y catalán.

c) «Quant al desenvolupament de les vocals finals, es dóna un contrast abrupte entre cat.-prov. i espanyol».

d) Són coincidències catalanoespanyoles $\mathrm{MB}>m$, la palatalització de -LL- i -NN-.

Etc. (Meyer-Lübke, 1998 [1925], §§ 4; 9; 39; 47; 48; 142; 143-144; 147).

En la tercera edición alemana de lo que en el castellano de A. Castro es la Introducción a la lingüística románica del sabio germano, decía él congruentemente consigo mismo cómo «el catalán es un dialecto provenzal que se extendió al retroceder los árabes» (Meyer-Lübke, W., 1926, p. 56).

El primer rechazo a algunas interpretaciones de este Das Katalanische se encuentra ya en la inmediata primera edición de la obra pidalina Orígenes del español: vid. sus epígrafes $\$ \S 100$ y 101, en el segundo de los cuales dice: «No encaja con la realidad la opinión de Meyer-Lübke [Das Katal., p. 106] que tiene la $l l$ - de las voces llana, llengua como un rasgo peculiarísimo del catalán, que le diferencia radicalmente del provenzal y del español; lejos de esto tenemos que considerar este rasgo como fundamentalmente hispánico».

De su parte Amado Alonso dio fe crítica de las posturas de Meyer-Lübke en su colaboración inmediata de la Revista de Filología Española de 1926. El 
joven Amado (treinta años) llevó a cabo una de las mejores reseñas -aunque con errores según Coromines- que hemos leído, y expuso entonces en páginas muy densas:

a) «Procura M.-L. demostrar [...] que «el sistema fonético del catalán es completamente galorrománico [,] no iberorrománico. Esto vale ante todo para el vocalismo tónico y para el ritmo, como se ve en el desarrollo de las vocales postónicas».

b) «Alguna conformidad catalano-provenzal enfrente del español se debió levantar en el ánimo del autor en los primeros momentos de meditación sobre la materia (conjetura Alonso), convenciéndole prematuramente del divorcio español-catalán, y esa poderosa impresión primera parece haber presidido obsesionante el curso de todo el trabajo». El autor se cree en la obligación de esta manera «de rebatir toda interdependencia español-catalana cada vez que se la encuentra en su camino, como si fuera posible que no existieran interdependencias lingüísticas entre dos regiones de estrecho contacto histórico y geográfico».

De tales interdependencias lengua española-lengua catalana el reseñista don Amado va destacando al hilo del propio M.-Lübke:

- cat. y esp. monoptongan como hemos dicho en b) arriba; provenzal no monoptonga.

- cat. y esp. pierden $-e(=\mathrm{c}$ arriba).

- lat. -mb- > esp. y catalán $m$, prov. $-m b-(=\mathrm{d}$ arriba, recogido también por entero en el escrito de Amado).

c) «No se podrían [ 'podrán'] tener por iberorrománicos todos los fenómenos catalanes».

d) «El considerar al catalán bajo el denominador provenzal ha sido un cómodo lugar común de muchos comparatistas que encontraban en ello una economía de esfuerzo: el catalán quedaba eliminado de sus cuadros».

e) Se sienta en la obra de M.-L. la ley de que «en la Comparatística sólo une la común transformación, no la conservación de un estado latino», mas el autor germano no la tiene en cuenta en sucesivos casos.

f) Basta en el libro reseñado «un rinconcillo provenzal coincidente con el catalán para asegurar su interdependencia, como basta también una parte peninsular divergente del catalán para asegurar su divorcio».

g) Las conclusiones del romanista germano «son notoriamente desproporcionadas. [...] Sirven tan sólo para asegurarnos de que el catalán y el español son lenguas distintas, nunca para demostrarnos que pertenecen a grupos lingüísticos diferentes».

(Alonso 1961: 12-13, 15-16, 35 y 42; cfr. también 18-21 y 27).

El hecho de la subagrupación románica del catalán le va a llevar a Amado a disentir de Meyer-Lübke, y a adherirse al Menéndez Pidal que acababa de publicar sus Orígenes del español -estamos en 1926-; veinte años más tarde 
vuelve don Amado y ya casi al final de su vida al asunto, y entonces proclama entre otras cosas, en una misma línea personal de coherencia:

e) «La Gotia románica, cuya capital estuvo sucesivamente en Toulouse, Barcelona y Toledo, se ofrece [...] como unidad lingüística, enfrente de la Franconia románica. [...] Con la unidad política se fomenta la coherencia de todo el territorio en el uso y desarrollo de la lengua, porque las acomodaciones del hablante con su sociedad, base tanto del funcionamiento como de la continua evolución de cada lengua, tienden a nivelarse por todo el reino» (pp. 95-96).

$\S 3$. Texto conocido no hace demasiados años aunque escrito fundamentalmente hacia 1938-1942, es el de la Historia de la lengua española de don Ramón Menéndez Pidal, la cual no deja de aludir a los rasgos y agrupación del idioma catalán.

El castellano -enumerará el autor- se asocia en varios rasgos con el catalán, y se detiene en dos, a saber:

- MB > m. «La asimilación [...] fue recibida con más intensidad en las costas de Tarragona, y con menor fuerza en el extremo interior de la provincia Tarraconense» (comp. Badía -2004-, cap. I/2).

- La forma -ariu > (carr)era, como el castellano y frente al provenzal carreira. Además Castilla «aparece más adelantada que Aragón y Cataluña en la monoptongación $\mathrm{EI}>e, \mathrm{AU}>o$ ».

En otro momento manifiesta Menéndez Pidal que «la tan debatida cuestión sobre clasificar el catalán como dialecto ibero-románico o como galo-románico carece de sentido científico» y «sólo sirvió a la política local»; seguramente se refiere a los años de la República o incluso a los de principios de siglo, en los que hubo de polemizar acerca de castellano y catalán: por él y a sugerencia suya había hablado Amado Alonso.

Y proclama cómo se da una «masa de fenómenos que el catalán ofrece peculiares de España toda o de su parte oriental y extraños a los dialectos languedocianos»: formaciones léxicas; «rasgos fonéticos que atribuimos a desarrollo visigótico-toledano, tales como $l$ - palatalizada y -as, -an > -es, -en comunes ambos con el asturiano y en parte con el aragonés».

Por igual hay otros rasgos de España extraños también a la Galia: «-ll- y -nn- palatalizadas-; [...]; -nd- > -nn-», etc. (Menéndez Pidal, 2005, I, pp. 378384 , 430-434, y los demás pasajes del propio volumen a los que remite su autor).

Don Ramón viene a argumentar entre líneas el iberorromanismo del catalán, lo que de manera un poco más expresa escribió y hemos visto Amado Alonso: que con la unidad política se fomenta la coherencia de todo el territorio [peninsular] en el uso y desarrollo de la lengua. 
$\S 4$. Saltamos ya a los años cincuenta, y en su umbral aparece un escrito de Vicente García de Diego cuyo título resulta ya un enunciado de tesis: «El catalán[,] habla hispánica pirenaica». El autor va proponiendo:

a) «Un conocimiento superficial del catalán ha extendido la idea de que el catalán es una deformación del provenzal, cuando la verdad es que tiene fisonomía peculiar y cuando la realidad histórica es que no ha sido importado, sino que ha nacido en su propio solar en derivación directa de los gérmenes latinos sedimentados en la romanización de Cataluña».

b) «La razón de la existencia del catalán [es...] el desarrollo lingüístico de una vitalidad propia, semejante en parte a sus vecindades hispanas y en parte a sus vecindades galas». La referencia a los rasgos de semejanza gala hacen esta conceptuación un tanto diferente a la pidalina, que subraya sobre todo el entroque español de la lengua catalana.

c) «La relativa unidad política de Provenza y Cataluña en el mismo tiempo no puede ser una prueba de unidad lingüística. [... El] catalán pirenaico no es el provenzal».

d) «Los dialectos pirenaicos, [...] a caballo de la gran cordillera no eran propiamente ni hispánicos ni galos, sino pirenaicos. Esta comunidad románica con sus naturales variantes era la continuación de otra gran comunidad prerrománica, de la que es supervivencia el vasco actual».

e) «Hay que explicar como una antigua relativa comunidad lingüística todas las hablas pirenaicas en ambas vertientes hasta el Mediterráneo; las primeras menos desvasquizadas, y las últimas romanizadas más prontamente y más intensamente».

Etc. (García de Diego 1950).

El conocimiento con mucho detalle de lo dialectal lleva a García de Diego a resultar menos hispanocéntrico que Pidal (y quizá que Amado Alonso, quien sigue muy fielmente lo que se deduce de los Orígenes pidalinos), y de ahí sus referencias a las que denomina las «vecindades galas» del idioma catalán.

§ 5. Enseguida aparecerán -y en los dos años consecutivos- otras tantas Gramáticas históricas del catalán, las de Antonio Badía y la de Francisco de Borja Moll, y ambas debían hacer algunas referencias a nuestro asunto. Badía estableció cómo

el catalán es pues una lengua románica, tan independiente como cualquiera de sus hermanas en el sentido de que [...] no ha de presentarse subordinada a ninguna otra. Su situación geográfica [...] hace que se encuentren en el catalán rasgos de los otros romances peninsulares y rasgos de romances ultrapirenaicos: lo que pudo haber sido su filiación puramente hispánica, vino mediatizada por su posición de puente hacia las demás provincias románicas, y además esa escisión inicial del bloque hispánico fué acentuada por el curso de la historia político-cultural, que situó en la órbita del sur de la antigua Galia el 
territorio que iba a ser dominio lingüístico catalán, precisamente en los siglos de elaboración de las lenguas neolatinas.

De acuerdo con estos hechos, ha resultado que una gran mayoría de rasgos idiomáticos evolutivos así como léxicos «son comunes» a catalán y a provenzal.

Badía se adhiere a Meyer-Lübke en que «la mayor parte de criterios gramaticales y léxicos del catalán son comunes también al provenzal», y de esta manera propone que no se hable de galorromanismo ni de iberorromanismo del catalán, ni de su pireneísmo salvo en tanto designaciones geográficas; lo que ocurre es que «hay un cierto eclecticismo del catalán, [...] se trata de una lengua hispánica con mayoría de rasgos lingüísticos ultrapirenaicos» (Badía, 1951, pp. 23-30).

Antonio Badía adopta una postura nacionalista al igual que Menéndez Pidal (aunque distinta): estamos ante una lengua independiente, aunque la historia toda la ha hecho a la vez española y ultrapirenaica.

Sólo en meses salía a la luz la obra paralela a la de Badía de F. de B. Moll, texto muy apreciado por don Ramón. Del presente escrito destacamos:

1. Moll da cuenta de cómo la identidad originaria del catalán con el provenzal quedó admitida en su día desde Milá hasta Morel-Fatio, y cómo distintamente Saroïhandy manifestaba a la letra que «no hay suficiente fundamento para excluir [la lengua hablada en Cataluña] del grupo de las lenguas hispánicas».

2. Sintetiza por su cuenta el mismo Moll: «Las continuas relaciones políticas, eclesiásticas, comerciales y culturales de Cataluña con los países ultrapirenaicos hasta principios del siglo XIII, explican el parentesco existente entre nuestra lengua y los dialectos lenguadocianos».

3. La acción reconquistadora en el territorio de Cataluña producía en las tierras nuevamente adquiridas una repoblación solamente parcial, ya que «en ellas se encontraban (por lo menos en los primeros siglos) núcleos de mozárabes que conservaban su lenguaje románico, idéntico o muy similar al de sus liberadores».

4. «El latín de que procede el catalán era más afín al latín de la Galia que al de Hispania» (para esta alusión $c f r$. el cap. 2 de Nadal-Prats 1982; vid. Moll, $\S \S 5-8)$. O sea, que las analogías idiomáticas fueron traídas por las relaciones históricas, y que luego con la Reconquista hubo una nivelación del hablar, aunque ya no en Valencia y en Baleares, de donde había desaparecido el habla romance.

$\S 6$. Un texto de relieve del propio Antonio Badía fue el que rotuló Fisiognómica comparada de las lenguas catalana y castellana, en el que -por lo que ahora nos importa más- va exponiendo:

a) El catalán resulta menos evolucionado y por tanto «es más fiel al punto de partido latino que el castellano». En su texto posterior «El català i les altres llengües romàniques» (1963) enunciará semejantemente el autor cómo «el català pertany $[. .$.$] a aquest món de fidelitat provada a la llengua de Roma».$ 
b) Teniendo presentes de manera implícita los Orígenes pidalinos, Badía escribe que «el catalán queda integrado en la órbita lingüística peninsular».

c) «La Tarraconense oriental se encontraba [...] mejor y más rápidamente comunicada con la metrópoli que el resto de la Península. Esta posición fluctuante de una tierra localizada en Hispania pero en el camino de Galia, se proyectaría en seguida en las características idiomáticas de su peculiar latín vulgar, el cual [...] no dejaba de representar [...] hábitos lingüísticos ultrapirenaicos» (de nuevo remitimos al cap. 2 de Nadal-Prats -1982-).

d) «La constitución de la lengua catalana se hace sobre todo bajo el signo del galorromanismo», de acuerdo con Meyer-Lübke.

e) «Así llegamos pues -proclama el autor- a la superación de galorromanismo e iberorromanismo del catalán: el catalán es una lengua-puente [...], una lengua de transición».

f) El catalán (antiguo y moderno) es comparable y afín al castellano antiguo, pero no al actual (Badía, 1955, pp. 12, 17, 18, 20, 22, 33; conclusiones en las pp. 52-53).

§7. En el conocido manual de Carlo Tagliavini (editado en 1949/1969) Orígenes de las lenguas neolatinas, se expone a la letra cómo en efecto el idioma catalán «es galorromance por sus orígenes, mas no puede ser clasificado como dialecto provenzal; es iberorromance por su posición geográfica, pero por sus caracteres peculiares y por razones históricas no puede ser contado entre las lenguas iberorromances»: es otra manera de indicar que se trata de una lengua de transición, acaso más cercana al provenzal.

§. Un estudioso de las presentes cuestiones, muy en detalle y riguroso, es Germán Colón. En sobre todo dos volúmenes suyos se ha referido a la materia, $\mathrm{y}$ vamos a dar idea de sus autorizadas posturas.

Un primer libro de conjunto es El léxico catalán en la Romania, en el que va exponiendo:

1. A partir de una lista de 24 palabras compuesta por Jud, nuestro presente autor concluye en que «podemos colocar 17 tipos lexicológicos $(70,8 \%)$ en la órbita galorrománica y $9(37,5 \%)$ en la iberorrománica». También cinco tipos «cuentan en ambos dominios».

2. «Las afinidades del léxico catalán con el de la Galorromania son evidentes y en ello los partidarios del «galorromanismo» de esa lengua llevan toda la razón [...]. Que una lengua romance situada en la Península Ibérica sea una lengua iberorrománica, geográficamente sí. Mas situarla por ello en el mismo plano lingüístico y en particular léxico que el castellano [...], ya no».

3. «[No] se me antoja muy feliz la metáfora de la «lengua puente», que podría convenir a cualquier lengua en relación a sus vecinas [...] del mismo grupo lingüístico». 
4. La relativa «hispanización» del catalán no es tan arrolladora como para hacerle perder su carácter específico.

5. «Es el galorrománico el que ofrece más afinidades» con el catalán. Esto es, «las soluciones léxicas del galorromance y del catalán avecinan [...] estrechamente los dos dominios. [...] La mayor parte de los tipos léxicos revelan una unidad catalano-occitana tan evidente que permite [...] hablar de un «continuum»».

6. En referencia al llamado pirenaico manifiesta G. Colón:«Mi oposición a esta manera de enfocar el problema es radical», pues los ejemplos que se habían dado «no resisten a un examen serio» (Colón, 1976, pp. 51-52, 60-61, 95, 106, 113-114 y 472, 146-147).

Etc.

§. El segundo volumen del prof. Colón, El español y el catalán, juntos y en contraste, nos enseña:

a) La lengua escrita y hablada en el Rosellón, en el Principado de Cataluña, en Valencia y en las Baleares, en Andorra, en Alguer, «es una», y ningún buen filólogo ni quiere ni puede negarlo.

b) G. Colón lleva a cabo una «somera caracterización» de la lengua catalana (pp. 36-38): no diptongación de las vocales tónicas; caída de las vocales finales átonas, excepto -a: foc, fam; etc. -la presente caracterización resulta bastante refractaria al resumen y remitimos directamente a ella (otra caracterización de la lengua se encuentra en la Gran Enciclopedia RIALP, y en la Gran Enciclopèdia Catalana -vol. 4- ).

c) «A partir de 1500 y hasta el segundo tercio del siglo XIX nuestra literatura no presenta ningún autor digno de mención» (Colón, 1989, pp. 32-33, $36-38,51)$.

$\S 10$. Temática análoga a la presente es la del artículo de Dan Munteanu «Sobre la posición del catalán en el conjunto de la Romania» (2004), quien además expone que en cuanto al vocabulario latino patrimonial, la lengua catalana forma parte del gupo iberorrománico.

Final. Tenemos previsto volver sobre este asunto en una segunda entrega

\section{BIBLIOGRAFÍA}

Alonso, A. (1961): Estudios lingüísticos. Temas españoles, Madrid, Gredos.

Recopilación de uso necesario.

Badía, A. (1951): Gramática histórica catalana, Barcelona, Noguer.

Obra que ha de consultarse necesariamente

Badía, A. (1955): Fisiognómica comparada de las lenguas catalana y castellana, Barcelona, Real Academia de Buenas Letras. Cfr. ampliamente del 
propio autor sus Moments clau de la història de la llengua catalana, Universitat de València, 2004.

Discurso y recopilación muy instructivos.

Colón, G. (1976): El léxico catalán en la Romania, Madrid, Gredos.

Otra agrupación útil de un autor escrupuloso.

Colón, G. (1989): El español y el catalán, juntos y en contraste, Barcelona, Ariel.

Bello volumen, sobre todo en la parte general.

García de Diego, V. (1950): «El catalán[,] habla hispánica pirenaica», Boletim de Filologia, pp. 55-60.

Menéndez Pidal, R. (1926): Orígenes del español, Anejo I de la RFE, Madrid, Centro de Estudios Históricos.

Obra maestra inexcusable, aunque haya que hacerle correcciones.

Menéndez Pidal, R. Historia de la lengua española, Madrid, Fundación Ramón Menéndez Pidal y RAE.

Obra póstuma y maestra, que sólo alcanza hasta hacia 1680.

Meyer-Lübke, W. (1926): Introducción a la lingüística románica, Madrid, Centro de Estudios Históricos.

Manual necesario, aun hoy día.

Meyer- Lübke, W. (1998): [1925]: Das Katalanische, trad. catalana -por la que citamos- de Guillem Calaforra, Barcelona, IEC.

Obra necesaria, que se halla a la cabeza de la presente temática

Moll, F. de B. (1952): Gramática histórica catalana, Madrid, Gredos.

Buen tratado acerca del asunto, estimado por Menéndez Pidal de manera expresa.

Munteanu, Dan (2004): «Sobre la posición del catalán en el conjunto de la Romania», AFA, LIX-LX, pp. 641-651.

Artículo de contenido semejante al nuestro, pero escrito -según resulta inevitable- con otro estilo.

Nadal, J. M. + Prats, M. (1982): Història de la llengua catalana, I, Barcelona, Edicions 62.

Una obra detallada y clara, muy atenta a lo histórico-cultural. 